\title{
The Studies on Molecular Geometries and Electronic Structures of Substituted meso-Catecholic Porphyrins: DFT Methods and NSD
}

\author{
Seung Hyun Park, Su Jin Kim, Jin Dong Kim, Sung-Bae Park, Do Sung Huh, Yong Key Shim, ${ }^{\dagger}$ and Sang Joon Choe \\ Department of Chemistry, Institute of Functional Haterials, Inje University, Kimhae 621-749, Korea \\ "E-mail: chemcsjainjeackr \\ School of Wano Engineering. Inje Lniversitvi, Kimhae 621-749, Korea \\ Received November 26, 2007
}

\begin{abstract}
Geometry optimizations and electronic stnicture calculations are reported for meso-tetraphenyl porphyrin (TPP) and a series of meso-substituted catecholic porphyrins (KP99150, KP99151, KP99152, KP99153, and KP99090) using density functional theory (DFT). The calculated B3LYP/RHF bond lengths are slightly longer than those of LSDA/RHF. The calculated electronic structures clearly show that TPP and meso-catecholic group contribute to $\pi$-electron conjugation along porphyrin ring for HOMO and LUMO. significantly reduced the HOMO-LUMO gap. The wavelength due to B3LYP energy gaps is favored with experimental value in Soret (B). and LSDA energy gaps are favored with experimental value in visible bands (Q). The electronic effect of the catecholic groups is to reduced energies of both the HOMOS and LUMOs. However, the distortion of porphyrin predominantly raises the energies of the HOMOs, so the net result is a large drop in HOMO and smaller drop in LUMO energies upon meso-substituted catecholic group of the porphy'rin macrocycle as shown in KP99151 and KP99152 of Figure 5(a). These results are in reasonable agreement with normal-coordinate stnictural decomposition (NSD) results. The HOMO-LUMO gap is an important factor to consider in the development of photody'namic therapy (PDT).
\end{abstract}

Key Words : meso-Catecholic porphyrins. Photodynanuic therapy (PDT). DFT

\section{Introduction}

Porphyrins and related molecules have fascinated theoretical chemists for many years. ${ }^{1}$ They and their derivatives are of importance not only in biological sy'stems. but also as organic semiconductors and non linear optical materials due to extended $\pi$-electron systems. Recently. many studies have been focused on the use of artificial photosynthesis to develop light-energy' conversion sy stems. ${ }^{2}$

Another attention has been focused on specific biomedical applications of pyrrolic based macrocycles as a result of their physical properties. One such field is photodynamic therapy (PDT) ${ }^{3-5}$ a new modality for the treatment of diseased tissue. wherein a combination of visible light and a photosensitizing drug are used to bring about a therapeutic response. The efficacy of such photosensitizers depends (among other factors) on absorption of light at wavelengths greater than $630 \mathrm{~nm}$. since at these wavelengths the natural chromophores in human and blood become relatively transparent. thereby allowing a greater depth of light penetration. PDT is based on accumulation of photosensitizer in malignant tissue after administration of the photosensitizer. Subsequent illumination with light of an appropriate wavelength creates a photochemical reaction: a so called photodynamic effect (photochemical reaction producing singlet oxygen) that results in tissue destruction. "This process is described in modified Jablonski diagram.

We are interesting the photosensitizers to absorb light at wavelengths greater than $630 \mathrm{~nm}$. since good photosensitizers may be related red shift of the longest wavelength $Q$ band (which enables lowers energy light to be used). Then we report DFT (B3LYP and LSDA) optimized geometries in order to examine which geometries of LSDA and B3LYP are favored with red shift of the longest wavelength $Q$ band.

In this study we carried out first-principle density functional theory (DFT) and Hartree-Fock (HF) studies of fundamental properties of free base porplyrin. TPP. and a series of meso-substituted catecholic porphyrins. We calculated the molecular geometries. electronic states. and eigenvalues of molecular orbitals near HOMO. This work is intended to serve as the basis for understanding the role of meso-catecholic group in providing insight of the ground state absorptions (both the Soret $\mathrm{B}$ band and $\mathrm{Q}$ band) from the calculated electronic states.

In the original Gouterman four orbital model, the Soret B band (the excitation from the singlet ground $S_{i}$ to first singlet state $S_{1}$ ) and the $Q$ band (from $S_{1}$ to $S_{2}$ ) can be explained in terms of excitations involving four orbitals. i.e. the occupied NHOMO (next highest occupied molecular orbital) and HOMO (highest occupied molecular). and the enpty LUMO (lowest unoccupied molecular orbital) and NLUMO (next lowest unoccupied molecular orbital). We consider the optical transition as the single electron transition with selection nules satisfied. The electronic structure calculations in this paper focused on these four orbitals.

Using DFT, we investigate geometries of the free-base porphyrin. TPP, $\mathrm{m}_{1}$-monocatecholic- $\mathrm{m}_{2}, \mathrm{~m}_{3} . \mathrm{m}_{4}$-triphenyl porphyrin (KP99150), $\mathrm{m}_{1,1} \mathrm{~m}_{-}$-dicatecholic- $\mathrm{m}_{3 .}, \mathrm{m}_{4}$-diphenyl porphyrin (KP99151), $\mathrm{m}_{1 .} \mathrm{m}_{3}$-dicatecholic- $\mathrm{m}_{2} . \mathrm{m}_{4}$-diphenyl porphyrin (KP99152), $\mathrm{m}_{1,1} \mathrm{~m}_{2}, \mathrm{~m}_{3}$-tricatecholic- $\mathrm{m}_{4}$-phenyl 


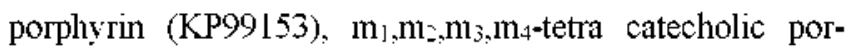
phyriu (KP99090). Our calculated geometries of porphyrin macrocycle rings compared with the experimental results of free-base porphyrin in in order to estimate the accuracy of calculated geometries of TPP and meso-catecholic porphyrins (KP99150. KP99151. KP99152, KP99153. KP99090. this number is a serial number in our laboratory), whose structures we are not measured experimentally as yet.

Based on these geometries. we examine their electronic structures. Koln-Sham eigenvalues and eigenstates of the four orbital (NHOMO. HOMO, LUMO. and NLUMO) in Gouterman's model.

In addition, non-planar deformations of the macrocycle are induced by steric forces arising from the catecholic substituents at the meso position. Then the optimized structures are analyzed using normal-coordinate structural decomposition (NSD). ${ }^{1 i b j}$, Since the catecholic substituents and the deformations of porphyrins ring in $\pi$ system have related to the visible band. we examine the effects of them to visible band.

\section{Computational Methods}

For DFT calculation, ${ }^{11.14}$ all structures were first optimized at the restricted Hartree-Fock (RHF) level. DFTs for optinization were used Local Spin Density Approxintation (LSDA) ${ }^{15}$ and Beck's Parameter Hybrid Functional using the LYP correlation Function (B3LYP). ${ }^{16,17}$ The split-valence and polarized $6-31 \mathrm{G}^{*}$ basis set were employed in the geometry optimizations. Hartree-Fock orbital energies can be used to reproduce ultraviolet photoelectron spectra patterns via Koopman's theorem (KT). DFT is based on densities rather than wave functions. and the Koln-Sham (KS) orbital energies. Wavelengths of Soret B and Q band were calculated from Gouterman (the Four Orbitals). ${ }^{\mathrm{s}}$
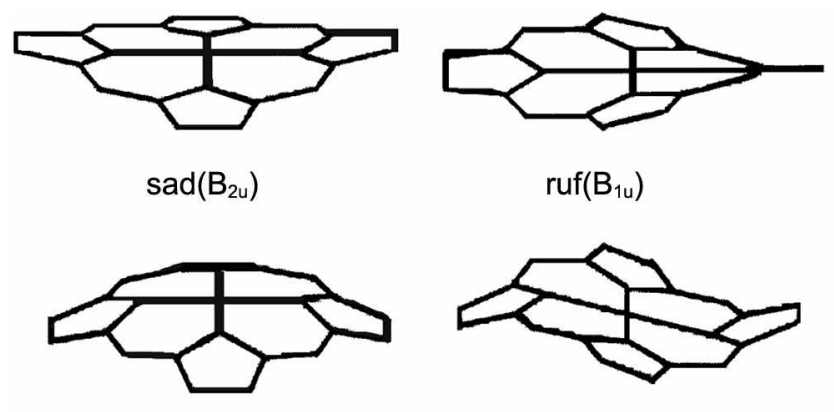

$\operatorname{dom}\left(A_{2 u}\right)$,

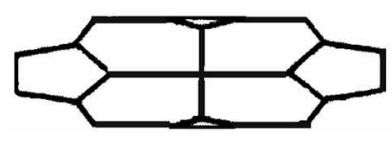

wav $(y)\left[E_{g}(y)\right]$
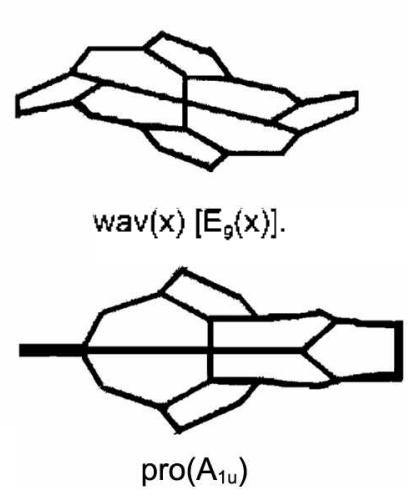

Figure 1. Illustration of out-of-plane eigenvector in the coordinate space, for each of the nomal deformations (sad, ruf, dom, wav( $x$ ), wav(y), and pro) used in describing the nomplanar distortions of porphyrin macrocvcle.
The DFT optimized structures are analyzed using normalcoordinate structural decomposition (NSD) ${ }^{\text {lit). }}$ NSD method characterizes the porphyrin conformation in terms of equilivalent displacements along the nomal coordinates porphyrin macrocycle. Typically. the largest static distortions of the porphyrin macrocycle occur along the softest normal modes. so that the greatest contributors to the nonplanar distortion are the lowest-frequency nomal coordinates of each out-of-plane symmetry type $\left(\mathrm{B}_{1 \mu} . \mathrm{B}_{2 i,}, \mathrm{~A}_{2 \mu} . \mathrm{E}_{\xi \text {, }}\right.$ and $A_{l i t}$ ). These deformations correspond to the symmetric distortions commonly observed in structure and naned ruffling (ruf). saddling (sad). doming (dom), waving (wav(x.y)), and propelling (pro) (see Figure 1). Mixed together, they give asymmetric macrocyclic distortions of various types, and adding the projections of the total distortions along only these six nomal coordinates typically simulates the actual out-of-plane distortion reasonable accurately. Calculations were performed using Gaussian program ${ }^{18}$ and NSD program on Silicon Graphics Computer system. The program searches for the optimum geometries using the criteria of ninimum energies

\section{Results and Discussion}

Molecular Geometries. The structural formula of mesosubstituted phenyl and catecholic porphyrins are shown in Figure 2. Meso-tetraphenyl porphyrin (TPP) and catecholic porphyrins (KP99150. KP99151, KP99152, KP99153. and KP99090) are obtained when R groups (RI, R2, R3, and R4) are substituted by phenyl and catecholic groups respectively. The geometry of free base porphyrin ( $\mathrm{PH}$ ) and numerical labels of carbon atoms are shown in Figure 3. The TPP and meso-catecholic porphyrins are derived by substituting hydrogen atoms $(\mathrm{H} 8)$ at four meso positions ( $\mathrm{C} 7)$ in $\mathrm{PH}$ by phenyl and catecholic groups. Table I shows the bond lengths and angles of free-base porplyyrin and TPP using HF

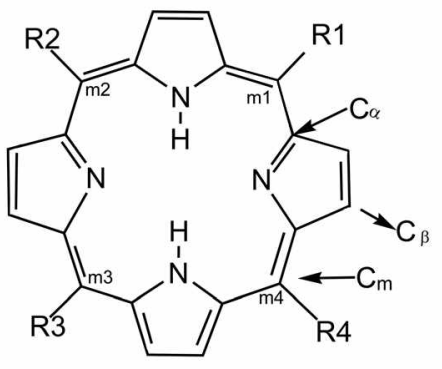

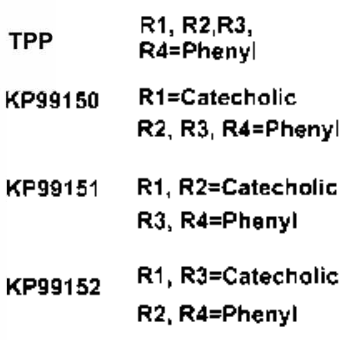

KP99153 R1, R2, R3=Catecholic R4=Phenyl

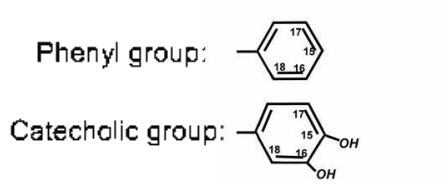

KF99090 R1, R2, R3, R4=Catechallc

Figure 2. Structural fonmula of the catecholic substituents at the meso-position of porphyrins and TPP: KP99150 ( $\mathrm{m}_{3}-\mathrm{mono}^{-}$

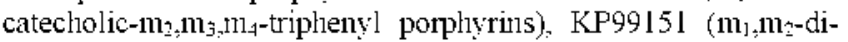
catecholic-m, $\mathrm{m}_{4}$-diphenyl porphynins), KP99152 (m, ms-dicatecholic-m, $\mathrm{m}_{1}, \mathrm{~m}_{\mathrm{A}}$ diphenyl porphysins), KP99153 ( $\mathrm{m}_{1}, \mathrm{~m}_{1}, \mathrm{~m}_{3}$-tricatecholic-m1,-monophenylporphyrins), KP99090 (m, $\mathrm{m}_{2, \mathrm{~m}}, \mathrm{~m}, \mathrm{~m}$-tetracatecholic porphyrins) 


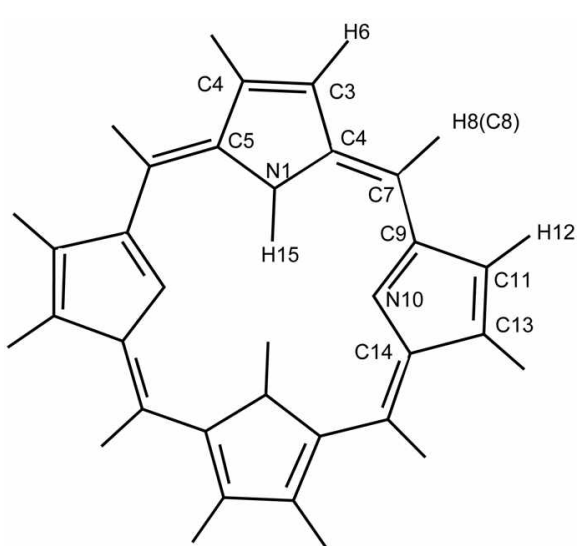

Figure 3. The geometry of free-base porphyrins with numerical label.

Table 1. Bond lengths $(A)$ and Angles (") of Free-Base Porphyin (PH) and tetra Phenyl Porphyrin (TPP) using HF and DFT Optimization with the Gaussian $6-3 \mathrm{IG}^{*}$ basis sets. The Nunerical Labels of Carbon Atoms are shown in Figure 3

\begin{tabular}{|c|c|c|c|c|c|c|}
\hline & \multicolumn{4}{|c|}{$\mathrm{PH}$} & \multicolumn{2}{|c|}{ TPP } \\
\hline & $\mathrm{HF}$ & 5.VI & LSDA// & $\mathrm{Esp}^{a x}$ & $\overline{\mathrm{B} 3 \mathrm{~L}}$ & LoL \\
\hline & & RHF & RHF & & RHF & RHF \\
\hline $\mathrm{Nl}-\mathrm{Hl} 5$ & 0.995 & 1.015 & 1.034 & - & 1.015 & 1.033 \\
\hline $\mathrm{N} 1-\mathrm{C} 2$ & 1.354 & 1.373 & 1.363 & 1.368 & 1.376 & 1.366 \\
\hline $\mathrm{C} 2-\mathrm{C} 3$ & 1.390 & 1.435 & 1.425 & 1.438 & 1.434 & 1.423 \\
\hline $\mathrm{C} 3-\mathrm{C} 4$ & 1.392 & 1.372 & 1.369 & 1.373 & 1.369 & 1.368 \\
\hline $\mathrm{C} 4-\mathrm{C} 5$ & 1.390 & 1.435 & 1.425 & 1.438 & 1.434 & 1.424 \\
\hline $\mathrm{C} 2-\mathrm{C} 7$ & 1.429 & 1.394 & 1.385 & 1.388 & 1.405 & 1.399 \\
\hline $\mathrm{C} 7-\mathrm{C} 9$ & 1.351 & 1.400 & 1.392 & 1.394 & 1.412 & 1.406 \\
\hline C9-NIO & 1.385 & 1.363 & 1.359 & 1.368 & 1.367 & 1.362 \\
\hline $\mathrm{N} 10-\mathrm{Cl} 4$ & 1.302 & 1.364 & 1.359 & 1.368 & 1.367 & 1.362 \\
\hline $\mathrm{C} 9-\mathrm{Cll}$ & 1.460 & 1.460 & 1.446 & 1.463 & 1.460 & 1.446 \\
\hline $\mathrm{C} 14-\mathrm{C} 13$ & 1.467 & 1.460 & 1.446 & 1.461 & 1.460 & 1.445 \\
\hline $\mathrm{C} 3-\mathrm{H} 6$ & 1.071 & 1.082 & 1.091 & - & 1.080 & 1.090 \\
\hline $\mathrm{C} 11-\mathrm{H} 12$ & 1.072 & 1.083 & 1.093 & - & 1.080 & 1.091 \\
\hline $\mathrm{C} 7-\mathrm{H} 8(\mathrm{C} 8)$ & 1.075 & 1.086 & 1.096 & - & 1.498 & 1.470 \\
\hline & 105.6 & 106.8 & 107.2 & 107.7 & 100.4 & 106.4 \\
\hline C9-N10-Cl4 & 106.4 & 105.7 & 104.7 & 105.7 & 1054 & 1054 \\
\hline $\mathrm{C} 2-\mathrm{NI}-\mathrm{C} 5$ & 111.8 & 109.9 & 110.2 & 109.6 & 110.8 & 110.8 \\
\hline $\mathrm{N} 10-\mathrm{C} 9-\mathrm{Cl}$ & 111.9 & 111.1 & 111.7 & 110.9 & 110.9 & 110.9 \\
\hline $\mathrm{C} 2-\mathrm{C} 3-\mathrm{C} 4$ & 108.5 & 108.0 & 107.7 & 107.5 & 108.2 & 108.2 \\
\hline $\mathrm{C} 9-\mathrm{Cl1}-\mathrm{Cl} 3$ & 106.0 & 106.2 & 106.0 & 106.3 & 106.3 & 106.3 \\
\hline $\mathrm{N} 1-\mathrm{C} 2-\mathrm{C} 7$ & 127.5 & 125.6 & 125.2 & 125.0 & 126.6 & 126.6 \\
\hline $\mathrm{N} 10-\mathrm{C} 9-\mathrm{C} 7$ & 125.5 & 125.5 & 125.8 & 125.1 & 126.1 & 126.1 \\
\hline $\mathrm{C} 2-\mathrm{C} 7-\mathrm{C} 9$ & 126.6 & 127.1 & 126.5 & 127.4 & 125.2 & 125.2 \\
\hline $\mathrm{H} 15-\mathrm{N} 1-\mathrm{C} 2$ & 124.1 & 124.6 & 124.9 & - & 124.6 & 124.6 \\
\hline $\mathrm{C} 2-\mathrm{C} 3-\mathrm{H} 6$ & 123.7 & 124.3 & 124.2 & - & 124.5 & 124.5 \\
\hline $\mathrm{C9}-\mathrm{Cll}-\mathrm{Hl}$ & 125.4 & 125.4 & 125.2 & - & 125.8 & 125.8 \\
\hline $\mathrm{C} 2-\mathrm{C} 7-\mathrm{H}$ & 117.3 & 1159 & 116.9 & - & 116.5 & 116.5 \\
\hline
\end{tabular}

and DFT optimization. The calculated B3LYP/RHF bond lengths are in excellent agreement with the experimental values ${ }^{10}$ of free-based porphyrin with maximum differences of only $0.006 \AA$. The maximum differences of LSDA/RHF bond length and $\mathrm{HF}$ are $0.02 \AA$. and $0.07 \AA$ respectively. Particularly, the LSDA/RHF bond lengths are slightly shorter than $\mathrm{x}$-ray crystallographic bond length, while the $\mathrm{B} 3 \mathrm{LYP} / \mathrm{RHF}$ bond lengths are slightly longer than those of LSDA/RHF: by $0.004-0.01 \AA$ for $\mathrm{C} \leftrightarrow \mathrm{N}$ bonds, $0.01-0.014$ $\AA$ for $\mathrm{C}_{\varnothing \beta} \mathrm{C}_{\beta}$ bonds. and 0.08-0.09 $\AA$ for $\mathrm{C}_{m e s}{ }^{-} \mathrm{C}_{\alpha e}$ bonds. From these results, we found that $\mathrm{B} 3 \mathrm{LYP} / \mathrm{RHF}$ bonds are in better agreement with experimental results ${ }^{19}$ than the LSDA/ /RHF and the $\mathrm{N}_{1}-\mathrm{C}_{2}$ and $\mathrm{C}_{m}-\mathrm{C}_{\alpha}$ bond lengths are slightly longer than those of experimental values. ${ }^{19}$ Then we are interested in the B3LYP/RHF and LSDA/RHF calculations.

Table 1 shows calculated results of TPP B3LYP optimized geometry. The $\mathrm{C}_{2}-\mathrm{C}_{7}$ and $\mathrm{C}_{7}-\mathrm{C}_{9}$ bond lengths are lengthened by 0.011 and $0.012 \AA$, respectively, as compared to those of $\mathrm{PH}$. due to phenyl group effects on the nearest $\mathrm{C}_{\text {merse }}-\mathrm{C}_{\alpha}$ bonds. The substitution also causes the bond lengths to be increased by $0.003-0.004 \AA$ for $\mathrm{N}-\mathrm{C}_{\alpha}\left(\mathrm{N}_{3}-\mathrm{C}_{2}, \mathrm{~N}_{1,1}-\mathrm{C}_{14}\right.$, and $\left.\mathrm{C}_{9}-\mathrm{N}_{10}\right)$ bonds, while the $\mathrm{C}_{2}-\mathrm{C}_{3} \cdot \mathrm{C}_{3}-\mathrm{C}_{4}$, and $\mathrm{C}_{4}-\mathrm{C}_{5}$ bond lengths are decreased by 0.001 .0 .003 , and $0.001 \AA$, respectively. The $\mathrm{C}_{9}-\mathrm{C}_{11}$ and $\mathrm{C}_{14}{ }^{-} \mathrm{C}_{1}$ ? bond lengths are unchanged. The bond angle of $\mathrm{C}_{2}-\mathrm{N}_{1}-\mathrm{C}_{5}$ is changed by 0.9 degree. 1.0 degree for $\mathrm{N}_{1}-\mathrm{C}_{2}-\mathrm{C}_{7}, 0.6$ degree for $\mathrm{N}_{10}-\mathrm{C}_{9}-\mathrm{C}_{7}$. and 1.9 degree for $\mathrm{C}_{2}-\mathrm{C}_{7}-\mathrm{C}_{9}$ bond. All other angles change by 0.10.4 degree.

Table 2 shows bond lengths and angles using B3LYP optimization. A series of meso-substituted catecholic porplyrins (KP99150. KP99151. KP99152, KP99153, and KP99090) increase the nearest $C_{2}-C_{7}$ and $C_{7}-C_{0}$ bond length in porplyrin ring by 0.012 to 0.014 for B3LYP, as compared to that of free-base porphyrin $(\mathrm{PH})$. due to catecholic group effects on the nearest $\mathrm{C}_{\text {mies }}-\mathrm{C}_{\alpha}$ bonds. The substitution also causes the bond lengths to be increased by $0.003-0.004 \AA$ for $\mathrm{N}-\mathrm{C}_{\alpha}\left(\mathrm{N}_{1}-\mathrm{C}_{2} \cdot \mathrm{N}_{10}-\mathrm{C}_{14}\right.$. and $\left.\mathrm{C}_{0}-\mathrm{N}_{10}\right)$ bonds. while the $\mathrm{C}_{2}-\mathrm{C}_{3}$, $\mathrm{C}_{5}-\mathrm{C}_{4}$, and $\mathrm{C}_{4}-\mathrm{C}_{5}$ bond lengths are decreased by 0.001 , 0.003 . and $0.001 \AA$, respectively. The $C_{9}-C_{11}$ and $C_{14}-C_{13}$ bond lengths are unchanged. The bond angle of $\mathrm{C}_{2}-\mathrm{N}_{1}-\mathrm{C}_{5}$ is changed by 0.8 degree for KP99153 and 0.1 degree for other molecules, 1.0-1.2 degree for $\mathrm{N}_{1}-\mathrm{C}_{2}-\mathrm{C}_{7}, 0.6-0.7$ degree for $\mathrm{N}_{1010}-\mathrm{C}_{0}-\mathrm{C}_{7}$, and 1.9-2.0 degree for $\mathrm{C}_{2}-\mathrm{C}_{7} \cdot \mathrm{C}_{0}$.

The bond lengths and bond angles of TPP and the catecholic porphyrins are listed in Table 1 and Table 2. The bond lengths of KP99150 are unchanged, as compared to those of TPP. due to catecholic group $\left(\mathrm{R}_{1}\right)$ effects at mesiposition in TPP as shown Figure 2. The $\mathrm{C}_{9}-\mathrm{N}_{10}-\mathrm{C}_{1+} \cdot \mathrm{C}_{9} \cdot \mathrm{C}_{11-}$ $\mathrm{C}_{13}$. and $\mathrm{C}_{2}-\mathrm{C}_{7}-\mathrm{C}_{0}$ bond angles are changed by 0.1 degree from TPP bond angles. All other angles are unchanged. The $\mathrm{N}_{1}-\mathrm{C}_{2} \cdot \mathrm{C}_{3}-\mathrm{C}_{4}, \mathrm{C}_{2}-\mathrm{C}_{7}$. and $\mathrm{C}_{7}-\mathrm{C}_{4}$ bond lengths of KP99151 are lengthened by $0.001 \AA$ from those of TPP. The $\mathrm{C}_{9}-\mathrm{N}_{1 j-}$ $\mathrm{C}_{14} \cdot \mathrm{C}_{9}-\mathrm{C}_{11}-\mathrm{C}_{13} \cdot \mathrm{N}_{1}-\mathrm{C}_{2}-\mathrm{C}_{7} \cdot \mathrm{N}_{10}-\mathrm{C}_{9}-\mathrm{C}_{7}$. and $\mathrm{C}_{2}-\mathrm{C}_{7}-\mathrm{C}_{9}$ bond angles are change by 0.1 degree. These results are due to two catecholic groups $\left(\mathrm{R}_{1} . \mathrm{R}_{2}\right)$ effects at meso-position. The $\mathrm{C}_{3}$ $\mathrm{C}_{4} \mathrm{C}_{4}-\mathrm{C}_{7}$. bond lengths of KP99152 are lengthened by 0.001 $A$ from those of TPP. The bond angle of $\mathrm{C}_{9}-\mathrm{N}_{11}{ }^{-} \mathrm{C}_{14} \cdot \mathrm{N}_{1}-\mathrm{C}_{2-}$ $C_{7}$. and $C_{2}-C_{7} \cdot C_{9}$ are changed by 0.1 degree. Different Geometry between KP9915I $\left(R_{1} . R_{2}\right)$ and KP99152 $\left(R_{1}, R_{3}\right)$ is due to different meso position of substituted catecholic group as shown in Figure 2. KP99153 has three catecholic groups which are $\mathrm{R}_{1}, \mathrm{R}_{3} . \mathrm{R}_{3}$ at meso position. The $\mathrm{N}_{1}-\mathrm{C}_{2} \mathrm{C}_{2}=$ $C_{7}$ and $C_{7}-C_{9}$ bond lengths are also lengthened by $0.001 \AA$ 
Table 2. Bond lengths ( $A$ ) and Angles $\left({ }^{\circ}\right)$ of KP99150, KP99151, $\mathrm{KP} 99152, \mathrm{KP} 99153$, and $\mathrm{KP} 99090$ using $\mathrm{B} 3 \mathrm{LYP} / 6-31 \mathrm{G}^{\circ} / \mathrm{RHF} / 6$ $31 \mathrm{G}^{*}$ Optimization. The Numerical Labels of Carbon Atoms are shown in Figure 3

\begin{tabular}{lccccc}
\hline & \multicolumn{5}{c}{ B3LYP/6-31G*/RHF $16-31 \mathrm{G}^{*}$} \\
\cline { 2 - 6 } & KP99150 KP99151 & KP99152 & KP99153 & KP99090 \\
\hline N1-H15 & 1.015 & 1.015 & 1.015 & 1.015 & 1.015 \\
N1-C2 & 1.376 & 1.377 & 1.376 & 1.377 & 1.377 \\
C2-C3 & 1.434 & 1.434 & 1.434 & 1.434 & 1.434 \\
C3-C4 & 1.369 & 1.370 & 1.370 & 1.369 & 1.369 \\
C4-C5 & 1.434 & 1.434 & 1.434 & 1.434 & 1.434 \\
C2-C7 & 1.406 & 1.406 & 1.406 & 1.406 & 1.406 \\
C7-C9 & 1.412 & 1.413 & 1.412 & 1.413 & 1.414 \\
C9-N10 & 1.367 & 1.367 & 1.367 & 1.367 & 1.366 \\
N10-C14 & 1.367 & 1.367 & 1.367 & 1.367 & 1.368 \\
C9-C11 & 1.460 & 1.460 & 1.460 & 1.460 & 1.460 \\
C14-C13 & 1.460 & 1.460 & 1.460 & 1.460 & 1.459 \\
C3-H6 & 1.080 & 1.080 & 1.080 & 1.080 & 1.080 \\
C11-H12 & 1.080 & 1.080 & 1.080 & 1.080 & 1.080 \\
C7-C8 & 1.498 & 1.496 & 1.498 & 1.498 & 1.496 \\
& & & & & \\
N1-C2-C3 & 106.4 & 106.4 & 106.4 & 106.4 & 106.4 \\
C9-N10-C14 & 105.5 & 105.5 & 105.5 & 105.5 & 105.5 \\
C2-N1-C5 & 110.8 & 110.8 & 110.8 & 110.7 & 110.8 \\
N10-C9-C11 & 110.9 & 110.9 & 110.9 & 110.9 & 110.9 \\
C2-C3-C4 & 108.2 & 108.2 & 108.2 & 108.2 & 108.2 \\
C9-C11-C13 & 106.4 & 106.4 & 106.3 & 106.4 & 106.4 \\
N1-C2-C7 & 126.6 & 126.7 & 126.7 & 126.8 & 126.7 \\
N10-C9-C7 & 126.1 & 126.2 & 126.1 & 126.2 & 126.2 \\
C2-C7-C9 & 125.1 & 125.1 & 125.1 & 125.2 & 125.2 \\
H15-N1-C2 & 124.5 & 124.6 & 124.6 & 124.7 & 124.5 \\
C2-C3-H6 & 124.5 & 124.5 & 124.5 & 124.4 & 124.4 \\
C9-C11-H12 & 125.7 & 125.8 & 125.9 & 125.8 & 125.8 \\
C2-C7-C8 & 116.6 & 116.6 & 116.6 & 116.3 & 116.6 \\
\hline & & & & & \\
& & & & & \\
& & & &
\end{tabular}

from TPP. The $\mathrm{C}_{9}-\mathrm{N}_{10}-\mathrm{C}_{14}, \mathrm{C}_{2}=\mathrm{N}_{1}-\mathrm{C}_{5}, \mathrm{~N}_{10}-\mathrm{C}_{9}-\mathrm{C}_{7}$, and $\mathrm{N}_{1}-\mathrm{C}_{2}-$ $\mathrm{C}_{7}$ bond angles are changed by 0.1 degree. The $\mathrm{N}_{1}-\mathrm{C}_{2}-\mathrm{C}_{7}$ bond angle is changed by 0.2 degree. All other bond angles and bond lengths unchanged from TPP. KP99090 has four catecholic groups which are $\mathrm{R}_{1}, \mathrm{R}_{2} . \mathrm{R}_{\hat{3}}$. and $\mathrm{R}_{4}$ at meso position. The $\mathrm{N}_{1}-\mathrm{C}_{3} \cdot \mathrm{C}_{2}-\mathrm{C}_{7} \cdot \mathrm{C}_{9}-\mathrm{N}_{11}, \mathrm{~N}_{10}-\mathrm{C}_{14}$, and $\mathrm{C}_{2}-\mathrm{C}_{7}$ bond lengths bond lengths are changed by $0.001 \AA$ from TPP. The $\mathrm{C}_{7}-\mathrm{C}_{9}$ bond length is changed by $0.002 \AA$. The $\mathrm{C}_{9}-\mathrm{N}_{10}-\mathrm{C}_{14}$. $\mathrm{C}_{1}-\mathrm{C}_{11}-\mathrm{C}_{13} \cdot \mathrm{N}_{1}-\mathrm{C}_{7}-\mathrm{C}_{7}$, and $\mathrm{N}_{10}-\mathrm{C}_{9}-\mathrm{C}_{7}$ bond angles bond are changed by 0.1 degree. The $\mathrm{C}_{2}-\mathrm{C}_{7}-\mathrm{C}_{8}$ bond angle of TPP is 116.5 degree. KP99150. and KP99151. KP99152. and KP99090 are equal to 116.6 degree. while KP99153 is 116.3 degree. The $\mathrm{C}_{7}-\mathrm{C}_{8}$ bond length of TPP. KP99150, KP99152. and KP99153 is equal to $1.498 \AA$. while KP99151 and $\mathrm{KP} 99090$ are equal to $1.496 \mathrm{~A}$. The $\mathrm{H}_{15}-\mathrm{N}_{1}-\mathrm{C}_{2}$ bond angle of KP99150. KP99153. and KP99090 is changed by 0.1 degree from TPP. The $\mathrm{C}_{2}-\mathrm{C}_{3}-\mathrm{H}_{16}$ bond angle of $\mathrm{KP} 99153$ and KP99090 is increased by 0.1 degree. The $\mathrm{C}_{1}-\mathrm{C}_{11}-\mathrm{H}_{12}$ of KP99150 and KP99152 is changed by 0.1 degree.

The LSDA optimized geometry of TPP is shown in Table 1. The $\mathrm{C}_{2}-\mathrm{C}_{7}$ and $\mathrm{C}_{7}-\mathrm{C}_{9}$ bond lengths are lengthened by 0.014 $\AA$, as compared to those of $\mathrm{PH}$, due to phenyl group effects on the nearest $\mathrm{C}_{\text {meso }}{ }^{\circ} \mathrm{C}_{\alpha}$ bonds. The substitution also causes
Table 3. Bond lengths $(\AA)$ and Angles ( ${ }^{\circ}$ of KP99150, KP99151. KP99152, KP99153, and KP99090 using LSDA/6-31 ${ }^{*} / / \mathrm{RHF} / 6-$ $3 \mathrm{IG}^{*}$ Optimization. The Numerical Labels of Carbon Atoms are shown in Figure 3

\begin{tabular}{lccccc}
\hline & \multicolumn{5}{c}{ LSDA/6-31G /RHF/6-31G- } \\
\cline { 2 - 6 } & KP99150 KP99151 & KP99152 & KP99153 & KP99090 \\
\hline N1-H15 & 1.033 & 1.033 & 1.033 & 1.033 & 1.033 \\
N1-C2 & 1.366 & 1.366 & 1.366 & 1.366 & 1.366 \\
C2-C3 & 1.423 & 1.423 & 1.424 & 1.424 & 1.423 \\
C3-C4 & 1.368 & 1.368 & 1.368 & 1.367 & 1.368 \\
C4-C5 & 1.424 & 1.423 & 1.424 & 1.424 & 1.424 \\
C2-C7 & 1.400 & 1.400 & 1.399 & 1.399 & 1.399 \\
C7-C9 & 1.406 & 1.407 & 1.406 & 1.406 & 1.405 \\
C9-N10 & 1.362 & 1.362 & 1.362 & 1.362 & 1.363 \\
N10-C14 & 1.361 & 1.361 & 1.362 & 1.363 & 1.363 \\
C9-C11 & 1.445 & 1.445 & 1.445 & 1.445 & 1.445 \\
C14-C13 & 1.445 & 1.445 & 1.445 & 1.445 & 1.445 \\
C3-H6 & 1.090 & 1.090 & 1.090 & 1.090 & 1.090 \\
C11-H12 & 1.090 & 1.091 & 1.091 & 1.091 & 1.091 \\
C7-C8 & 1.470 & 1.467 & 1.470 & 1.472 & 1.471 \\
& & & & & \\
N1-C2-C3 & 107.1 & 107.1 & 107.0 & 107.0 & 107.1 \\
C9-N10-C14 & 104.8 & 104.8 & 104.7 & 104.8 & 104.8 \\
C2-N1-C5 & 110.2 & 110.2 & 110.2 & 110.1 & 110.2 \\
N10-C9-C11 & 111.4 & 111.4 & 111.5 & 111.4 & 111.5 \\
C2-C3-C4 & 107.8 & 107.8 & 107.8 & 107.9 & 107.8 \\
C9-C11-C13 & 106.1 & 106.2 & 106.1 & 106.2 & 106.1 \\
N1-C2-C7 & 126.1 & 126.1 & 126.1 & 126.6 & 126.3 \\
N10-C9-C7 & 126.2 & 126.3 & 126.1 & 126.5 & 126.4 \\
C2-C7-C9 & 124.3 & 124.3 & 124.2 & 124.9 & 124.5 \\
H15-N1-C2 & 124.6 & 124.7 & 124.6 & 125.5 & 124.4 \\
C2-C3-H6 & 124.2 & 124.2 & 124.1 & 124.0 & 124.1 \\
C9-C11-H12 & 125.4 & 125.4 & 125.5 & 125.5 & 125.5 \\
C2-C7-C8 & 117.1 & 117.0 & 117.0 & 116.5 & 116.8 \\
\hline & & & & &
\end{tabular}

the bond lengths to be increased by $0.003 \AA$ for $\mathrm{N}-\mathrm{C}_{\alpha}\left(\mathrm{N}_{1}\right.$ $C_{2}$. $N_{10}-C_{14}$ and $\left.C_{9}-N_{10}\right)$ bonds. while the $C_{2}-C_{3}$ and $C_{3}-C_{4}$ bond lengths are decreased by 0.002 and $0.001 \AA$ and $C_{4}-C_{5}$ bond length is increased by $0.013 \AA$. The $C_{9}-C_{11}$ bond lengths are unchanged. The bond angle of $\mathrm{C}_{2}-\mathrm{N}_{3}-\mathrm{C}_{5}$ is changed by 0.6 degree. 1.4 degree for $\mathrm{N}_{1}-\mathrm{C}_{2}-\mathrm{C}_{7}$. and 1.3 degree for $\mathrm{C}_{2}-\mathrm{C}_{7}-\mathrm{C}_{9}$ bond angle. All other angles changed by 0.3-0.8 degree.

Table 3 shows bond lengths and angles using LSDA optimization. A series of meso-substituted catecholic porphyrins (KP99150. KP99151, KP99152. KP99153, and KP99090) increase the nearest $C_{7}-C_{7}$ and $C_{7}-C_{9}$ bond length in porphyrin ring by 0.014 to $0.015 \AA$ for LSDA, as compared to that of free-base porphyrin $(\mathrm{PH})$, due to catecholic group effects on the nearest $C_{\text {mess }}-C_{\alpha}$ bonds.

The bond lengths and bond angles of TPP and the catecholic porphyrins are listed in Table 1 and Table 3 . The $\mathrm{C}_{2}-\mathrm{C}_{7}, \mathrm{~N}_{10}=\mathrm{C}_{14}$. and $\mathrm{C}_{9}-\mathrm{C}_{11}$ bond lengths of KP99150 are changed by $0.001 \AA$. as compared to those of TPP. due to catecholic group $\left(\mathrm{R}_{1}\right)$ effects at meso-position in TPP as shown Figure 2. All other bond lengths are unchanged. The $\mathrm{N}_{1}-\mathrm{C}_{2}-\mathrm{C}_{3}$ and $\mathrm{C}_{4}-\mathrm{C}_{7}-\mathrm{C}_{9}$ bond angles are changed by 0.7 and 0.9 degree from TPP bond angles. The $\mathrm{C}_{9}=\mathrm{N}_{14 i-} \mathrm{C}_{1+}, \mathrm{C}_{2}=\mathrm{N}_{1}-$ 
$\mathrm{C}_{5}$. and $\mathrm{C}_{2}-\mathrm{C}_{7}-\mathrm{C}_{8}$ bond angles are changed by 0.6 degree. All other angles changed by $0.3-0.5$ degree. The $\mathrm{C}_{4}-\mathrm{C}_{5}, \mathrm{~N}_{10}-\mathrm{C}_{14}$. and $C_{-}-C_{11}$ bond lengths of KP99151 are reduced by $0.001 \AA$ from those of TPP. The $\mathrm{C}_{7}-\mathrm{C}_{8}$ bond length is reduced by $0.003 \AA$. The $C_{7}-C_{9}$ and $C_{3}-C_{7}$ bond lengths are lengthened by $0.001 \AA$. All other bond lengths are unchanged from those of TPP. The $\mathrm{N}_{1}-\mathrm{C}_{2}-\mathrm{C}_{3}$ and $\mathrm{C}_{2}-\mathrm{C}_{7}-\mathrm{C}_{9}$ bond angles are change by 0.7 and 0.9 degree, respectively. The $C_{5}-N_{10}-C_{14}$ and $\mathrm{C}_{2}-\mathrm{N}_{1}-\mathrm{C}_{5}$ bond angles are increased by 0.6 degree. All other angles are changed by $0.1-0.5$ degree. These results are due to two catecholic groups $\left(\mathrm{R}_{l}, \mathrm{R}_{2}\right)$ effects at mesoposition. The $\mathrm{C}_{2}-\mathrm{C}_{3}$ bond lengths of KP99152 are lengthened by $0.001 \AA$ from those of TPP. The $\mathrm{C}_{4}-\mathrm{C}_{11}$ bond lengths are reduced by $0.001 \AA$. All other bond lengths are unchanged from those of TPP. The bond angle of $\mathrm{C}_{5-1}-\mathrm{N}_{10}-\mathrm{C}_{14}$ is changed by 0.7 degree. The $\mathrm{N}_{1}-\mathrm{C}_{2}-\mathrm{C}_{3}$ and $\mathrm{C}_{2}-\mathrm{N}_{1}-\mathrm{C}_{5}$ bond angles are changed by 0.6 degree. The $\mathrm{C}_{2}-\mathrm{C}_{7}-\mathrm{C}_{9}$ bond angle is changed by 1.0 degree. All other bond angles are changed by 0.3-0.5 degree. Different geometry between KP99151 $\left(\mathrm{R}_{1}, \mathrm{R}_{2}\right)$ and $\mathrm{KP} 99152\left(\mathrm{R}_{1}, \mathrm{R}_{3}\right)$ is due to different meso position of substituted catecholic group. KP99153 has three catecholic groups which are $\mathrm{R}_{1}, \mathrm{R}_{2}, \mathrm{R}_{3}$ at meso position. The $\mathrm{C}_{2}-\mathrm{C}_{3}$ and $\mathrm{N}_{10}-\mathrm{C}_{14}$ bond lengths are lengthened by $0.001 \AA$ from TPP. The $\mathrm{C}_{3}-\mathrm{C}_{4}$ and $\mathrm{C}_{9}-\mathrm{C}_{11}$ are reduced by $0.001 \AA$. All other bond lengths are unchanged from TPP. The $\mathrm{C}_{2}-\mathrm{N}_{3}-\mathrm{C}_{5}$ bond angle is changed by 0.7 degree from TPP. The $\mathrm{N}_{1}-\mathrm{C}_{2}$ $\mathrm{C}_{3}$ and $\mathrm{C}_{9}-\mathrm{N}_{10}-\mathrm{C}_{14}$ bond angles are changed by 0.6 degree. All other angles are changed by 0.1-0.5 degree. KP99090 has four catecholic groups $\left(R_{1}, R_{2} . R_{3} . R_{+}\right)$at meso position as shown Figure 2. The $\mathrm{C}_{7}-\mathrm{C}_{9} \cdot \mathrm{C}_{9}-\mathrm{N}_{1016} \mathrm{~N}_{10}-\mathrm{C}_{14}$. and $\mathrm{C}_{9}-\mathrm{C}_{11}$ bond lengths bond lengths are changed by $0.001 \AA$ from TPP. The $\mathrm{N}_{1}-\mathrm{C}_{2}-\mathrm{C}_{3} . \mathrm{C}_{9}-\mathrm{N}_{10}-\mathrm{C}_{1+}, \mathrm{C}_{2}-\mathrm{N}_{1}-\mathrm{C}_{5}$, and $\mathrm{C}_{2}-\mathrm{C}_{7}-\mathrm{C}_{9}$ bond angles bond are changed by $0.6-0.7$ degree. The $\mathrm{C}_{2}-\mathrm{C}_{7}-$ $\mathrm{C}_{8}$ bond angle of TPP and KP99153 is equal to 116.5 degree. 171.1 for KP99150, 117.0 degree for KP9915I and KP99152. and 116.8 degree for $\mathrm{KP} 99090$. The $\mathrm{C}_{7}-\mathrm{C}_{8}$ bond length of TPP, KP99150, and KP99152 is equal to $1.470 \AA .4 .467 \AA$ for KP99151. 1.472 $\AA$ for KP99153, and $1.471 \AA$ for KP99090.

Table 4 shows that the distances $(A)$ between protonated nitrogens. and those between unprotonated nitrogens in porphyrin rings of calculated molecule syrstems. The distances of them due to substitute phenyl and catecholic group at meso positions are decreased from those of $\mathrm{PH}$. Particularly. for B3LYP method. the distances between the protonated nitrogens in KP99151 are $4.225 \mathrm{~A}$ and all other molecules are 4.221-4.222 $\mathrm{A}$. while those between the unprotonated nitrogens are $4.079 \AA$ and other molecules are 4.080-4.081 A. For LSDA method the distances between the protonated nitrogens in KP99151 are $4.208 \mathrm{~A}$ and all other molecules are 4.196-4.198 A while those between the unprotonated nitrogens are 3.994 $\AA$ and other molecules are 3.999-4.000 A. Specially the distance of unprotonated nitogens is 4.005 $A$ in KP99153, and 4.007 for KP99090.

The effects of the substituted phenyl and catecholic groups are minimal. However. although the nearest $\mathrm{C}_{m e s i}-\mathrm{C}_{\alpha}$ bond lengths are lengthened by $0.011-0.012 \AA$ from those of $\mathrm{PH}$
Table 4. The Distances ( $A$ ) between Protonated nitrogens, and those between Unprotonated nitrogens in Porphyrin rings of calculated molecule systems

\begin{tabular}{|c|c|c|c|c|}
\hline \multirow{2}{*}{ Molecules } & \multicolumn{2}{|c|}{ B3LYP/RHF } & \multicolumn{2}{|c|}{ LSDA/RHF } \\
\hline & $\mathrm{HN}-\mathrm{NH}^{a}$ & $\mathrm{~N}-\mathrm{N}^{b}$ & $\mathrm{HN}-\mathrm{NH}^{\prime \prime}$ & $\mathrm{N}-\mathrm{N}^{b}$ \\
\hline $\mathrm{PH}$ & 4.234 & 4.059 & 4.207 & 3.972 \\
\hline TPP & 4.222 & 4.079 & 4.205 & 3.993 \\
\hline KP99150 & 4.222 & 4.080 & 4.198 & 3.999 \\
\hline KP99151 & 4.225 & 4.079 & 4.208 & 3.994 \\
\hline KP99152 & 4.222 & 4.080 & 4.198 & 4.000 \\
\hline KP99153 & 4.222 & 4.081 & 4.197 & 4.005 \\
\hline KP99090 & 4.221 & 4.081 & 4.196 & 4.0007 \\
\hline
\end{tabular}

"HN-NH: The distances between protonated nitrogens in porphyrin rings of molecules. ' $\mathrm{N}-\mathrm{N}$ : The distances between unprotonated nitrogen in porlyyrin rings of molecules.

for the B3LYP and $0.014 \AA$ for the LSDA in tetra phenyl porphyrin, and $\mathrm{C}_{n e s}-\mathrm{C}_{\alpha}$ bond lengths are change by 0.012 $0.014 \AA$ for B3LYP and 0.014-0.015 $\AA$ for LSDA in catecholic porphyrin systems.

Comparing to phenyl and catecholic group as shown in Figure 2, $C_{15}-C_{16}, C_{15}-C_{17}$. and $C_{16}-C_{18}$ bond lengths are equal to $1.396 \AA$ in phenyl group in TPP, while $\mathrm{C}_{15}-\mathrm{C}_{16} \mathrm{C}_{15-}$ $\mathrm{C}_{17}$ and $\mathrm{C}_{16} \mathrm{C}_{18}$ bond lengths in catecholic group is $1.402 \AA$. $1.382 \AA, 1.387 \AA$. respectively. The bond lengths of catecholic group are increase, as compared to those of phenyl

Table 5. The Sign Reversed eigenvalues (in eV) of Goutemnan's four orbitals [NHOMO (b2) to NLUMO (c2)] calculated using Hartree-Fock (HF) and Density Functional Theory (DFT) with 6$31 \mathrm{G}^{*}$ basis set. The Last two row are the HOMO-LUMO Gap $\left(\Delta \varepsilon_{i l}\right)$, HOMO-NLUMO Gap $\left(\Delta \varepsilon_{p y}\right)$, NHOMO-LUMO Gap ( $\left.\Delta \varepsilon_{, H}\right)$, NHOMO-NLUMO Gap $\left(\Delta \varepsilon_{, i j i j}\right)$, calculated from HF and DFT. Parentheses are wavelengths (in nm)

\begin{tabular}{|c|c|c|c|c|c|}
\hline & \multicolumn{3}{|c|}{ Pophyrin } & \multicolumn{2}{|c|}{ TPP } \\
\hline & $\mathrm{HF}$ & $\begin{array}{c}\text { B3LYP// } \\
\text { RHF }\end{array}$ & $\begin{array}{c}\text { LSDA// } \\
\text { RHF }\end{array}$ & $\begin{array}{c}\text { B3LYP// } \\
\text { RHF }\end{array}$ & $\begin{array}{c}\text { LSDA// } \\
\text { RHF }\end{array}$ \\
\hline b2 & 6.904 & 5.296 & 5.606 & 5.207 & 5.525 \\
\hline bl & 6.416 & 5.149 & 5.336 & 4.899 & 5.051 \\
\hline $\mathrm{cl}$ & -0.877 & 2.235 & 3.366 & 2.201 & 3.361 \\
\hline$c 2$ & -1.001 & 2.219 & 3.344 & 2.192 & 3.351 \\
\hline $\begin{array}{l}\text { Q(Visibl } \\
\text { Exper }\end{array}$ & \multicolumn{3}{|c|}{$1.977(627)^{a+1}, 2.022(613)^{a . c}$} & \multicolumn{2}{|c|}{$1.937(640)^{6 t}$} \\
\hline \multicolumn{6}{|l|}{ Calc } \\
\hline$\Delta \varepsilon_{i}$ & $\begin{array}{l}7.417 \\
(167)\end{array}$ & $\begin{array}{l}2.930 \\
(423)\end{array}$ & $\begin{array}{l}1.992 \\
(622)\end{array}$ & $\begin{array}{l}2.707 \\
(458)\end{array}$ & $\begin{array}{l}1.700 \\
(729)\end{array}$ \\
\hline$\Delta \varepsilon_{v i}$ & $\begin{array}{l}7.293 \\
(170)\end{array}$ & $\begin{array}{l}2.914 \\
(425)\end{array}$ & $\begin{array}{l}1.970 \\
(629)\end{array}$ & $\begin{array}{l}2.698 \\
(459)\end{array}$ & $\begin{array}{l}1.690 \\
(733)\end{array}$ \\
\hline \multicolumn{6}{|l|}{$\mathrm{B}$ (Soret) } \\
\hline Calc & & & & & \\
\hline$\Delta \varepsilon_{n, h}$ & $\begin{array}{l}7.781 \\
(159)\end{array}$ & $\begin{array}{l}3.061 \\
(405)\end{array}$ & $\begin{array}{l}2.240 \\
(553)\end{array}$ & $\begin{array}{l}3.006 \\
(412)\end{array}$ & $\begin{array}{l}2.164 \\
(573)\end{array}$ \\
\hline$\Delta \varepsilon_{n}(h)$ & $\begin{array}{l}7.905 \\
(157)\end{array}$ & $\begin{array}{l}3.077 \\
(403)\end{array}$ & $\begin{array}{l}2.262 \\
(548)\end{array}$ & $\begin{array}{l}3.015 \\
(411)\end{array}$ & $\begin{array}{l}2.174 \\
(570)\end{array}$ \\
\hline
\end{tabular}

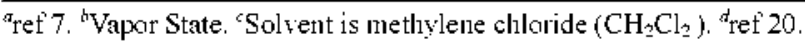


group. It seem to contribute to resonance effects of hydro oxide group in catecholic group.

Electronic Structures. Table 5 shows the sign reversed eigenvalues (in eV) of Gouterman s four orbitals ${ }^{5}$ [NHOMO (b2), HOMO (bl), LUMO (cl) (NLUMO (c2)] calculated by Hartree-Fock (HF) and Density Functional Theory (DFT) for Porphyrin and TPP. There are two nearly degenerated HOMOs (bl and b2) and LUMOs ( $\mathrm{cl}$ and $\mathrm{c} 2$ ). The $\Delta \varepsilon_{n l}$ and $\Delta \varepsilon_{m i n}$ are the states associated with visible bands. and $\Delta \varepsilon_{i n \text { l. }}$ $\Delta \varepsilon_{\text {finin }}$ correspond to Soret bands. ${ }^{s}$ The HF results show significant overestimation of the HOMO-LUMO gap. B3LYP HOMO-LUMO $\left(\Delta \varepsilon_{n l}\right)$ and NHOMO-LUMO $\left(\Delta \varepsilon_{n i n}\right)$ energy gaps are $2.930 \mathrm{eV}$ and $3.06 \mathrm{l} \mathrm{eV}$. which correspond to wavelength of 423 and $405 \mathrm{~nm}$, respectively. $\Delta \varepsilon_{n l}$ and $\Delta \varepsilon_{\text {in }}$ energy gaps for LSDA are $1.992 \mathrm{eV}$ and $2.240 \mathrm{eV}$. which correspond to wavelength of 629 and $553 \mathrm{~nm}$, respectively. The wavelength due to B3LYP energy gaps are agreement with experimental value ${ }^{7}$ in Soret (B), and LSDA energy gaps are agreement with experimental value in visible bands (Q). Other hand. the wave length due to B3LYP energy gaps show $31 \%$ deviation from experimental value in $Q$ bands. while LSDA energy gaps show $41 \%$ deviation from experimental in B bands. The LSDA $\Delta \mathcal{e}_{n l}$ bands for TPP show as much as $17 \%$ red shift relative to porphyrin and $14 \%$ deviation from experimental in $\mathrm{Q}$ band, while B3LYP $\Delta \varepsilon_{\text {in }}$ band is agreement with experimental value ${ }^{\text {ij }}$ However. LSDA energy gaps are a favorite with visible bands. while B3LYP energy gaps are a favorite with Soret bands. We have an interest in visible bands for PDT.

Table 6 shows Gouternan's four orbitals calculated using LSDA/RHF and B3LYP//RHF for the substituted mesocatecholic porphyrins. $\Delta \varepsilon_{n l}$ bands for KP99150 show as much as red shift $19 \%$ relative to porphyrin. $25 \%$ for KP99151. 22\% for KP99152, $23 \%$ for KP99153, and $27 \%$ for KP99090. respectively.

Comparing measured experimental and calculated value. the wavelength due to LSDA energy gaps are agreentent with experimental value within maximum error of $19 \%$.

$\Delta \varepsilon_{n}$ and $\Delta \varepsilon_{\mathrm{tst}}$ bands for KP99150 show as much as red shift $2.0 \%-2.7 \%$ relative to TPP. $6.6 \%-6.7 \%$ for KP99151.
$4.1 \%-6.4 \%$ for KP99152. $5.2 \%-5.6 \%$ for KP99153. and $8.0 \%-8.5 \%$ for KP99090, respectively. The absorption spectrum shifts to the red as the size of the $\mathrm{OH}$ substituents increases. Although the KP9915l in size $\mathrm{OH}$ is equal to KP99152, $\Delta e_{n l}$ band of KP9915l shows more red shifts than that of KP99152. It is due to $\pi$-overlap angle (or $\mathrm{N}-\mathrm{C}_{\alpha}-\mathrm{C}_{m}$ $\mathrm{C}_{\alpha}$ torsion angle) which characterizers the degree of $\pi$ overlap between the pyrrole rings. Calculated $\pi$-overlap angle by LSDA theory of KP99151 and KP99152 is 8.4 degree and 8.1 degree. respectively. Then. $\Delta \varepsilon_{n l}$ band of KP99151 shows more red shifts than that of KP99152 because $\pi$-overlap angle of KP99151 is more than that of KP99152. It is a reasonable agreement with shehutt et al ${ }^{21}$

Figure 4 shows the three-dimensional (3-D) contours of the Gouterman four orbitals with a wave-function value of 0.01 and 0.02 a.u. for free-base porplyrins $(\mathrm{PH})$. meso-tetra phenyl porphyrin (TPP). and meso-tetracatecholic porphyrin (KP99090) calculated from LSDA theory. The charge distributions of these orbitals on the meso-substituted phenyl and catecholic group are clearly observed. and it is noted that the transition from HOMO to LUMO is accompanied by outward charge transfer. A significant additional red shift is noted for the HOMO-LUMO gap relative to porplyrin, as listed in Table 5-6. Conjugated $\pi$ is clearly extended between the molecular systems, since the larger delocalization results in a narrower energy gap.

In order to estimate non-planar deformations of the macrocycle induced by steric forces arising from the phenyl and catecholic substituents at the meso positions, we analyzed using NSD. ${ }^{1 ; b), 9,1 i j}$ Both the LSDA and B3LYP structures (TPP, KP99150. KP99151. KP99152, KP99153. and KP99090) are analyzed using NSD ${ }^{1,0,9.11}$ as shown in Figure 5. Conparing LSDA and B3LYP structures, non-planar defonmations for LSDA are a larger than those of B3LYP structures. However, although non-planar deformations of the porplyrin macrocycle are shown similar tendency by the substituents at meso positions, LSDA defomations are relatively correspond to visible $Q$ band. NSD results show a large change in out-of-plane deformations at KP99152 than that of KP99151. Specifically for KP99152, saddling is $1.04 \mathrm{~A}$, nuffling is 0.01

Table 6. The Sign reversed eigenvalues (in eV) of Goutennan,s four orbital [NHOMO (b2) to NLUMO (c2)] calculated using LSDA/RHF and B3LYP/RHF. Calculated $\Delta \varepsilon_{h}$ and $\Delta \varepsilon_{h+3}$ are the state associated with visible band, and $\Delta \varepsilon_{m,} \Delta \varepsilon_{n i j h}$ by correspond to the Soret bands. Parentheses are wavelengths (in 1 min)

\begin{tabular}{|c|c|c|c|c|c|c|c|c|c|c|c|}
\hline & \multicolumn{5}{|c|}{ 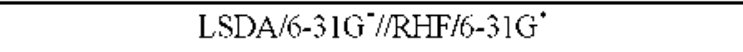 } & & \multicolumn{5}{|c|}{ BSLYP/6-31G $/ /$ RHF $/ 6-31 G^{*}$} \\
\hline & KP99150 & KP99151 & KP99152 & KP99153 & KP99090 & & KP99150 & KP99151 & KP99152 & KP99153 & KP999090 \\
\hline $\mathrm{b} 2$ & 5.438 & 5.436 & 5.392 & 5.360 & 5.381 & $\overline{b 2}$ & 5.157 & 5.207 & 5.155 & 5.159 & 5.210 \\
\hline bl & 4.929 & 4.878 & 4.844 & 4.811 & 4.778 & bl & 4.838 & 4.849 & 4.821 & 4.822 & 4.850 \\
\hline $\mathrm{cl}$ & 3.283 & 3.289 & 3.254 & 3.209 & 3.213 & $\mathrm{cl}$ & 2.152 & 2.203 & 2.157 & 2.152 & 2.204 \\
\hline$c 2$ & 3.261 & 3.279 & 3.212 & 3.194 & 3.211 & $c 2$ & 2.143 & 2.199 & 2.141 & 2.145 & 2.198 \\
\hline \multicolumn{6}{|c|}{ Q(Visible) } & \multicolumn{6}{|c|}{$\mathrm{B}$ (Soret) } \\
\hline Expa & $1.918(646)$ & $1.898(653)$ & $1.915(647)$ & $1.907(650)$ & $1.867(664)$ & Exp & $2.965(+18)$ & $2.951(420)$ & $2.951(420)$ & $2.944(421)$ & $2.944(421)$ \\
\hline$\Delta \varepsilon_{14}$ & $1.668(743)$ & $1.595(777)$ & $1.632(759)$ & $1.617(767)$ & $1.567(791)$ & $\Delta \varepsilon_{n v}$ & $3.005(412)$ & $3.004(413)$ & $2.998(413)$ & $3.007(412)$ & $3.006(412)$ \\
\hline$\Delta \varepsilon_{i n I^{\prime}}$ & $1.646(753)$ & $1.585(782)$ & $1.590(780)$ & $1.602(774)$ & $1.565(792)$ & $\Delta \varepsilon_{\left.n \mid a^{\prime}\right)}$ & $3.014(411)$ & $3.008(+12)$ & $3.01+(411)$ & $3.014(+11)$ & $3.012(412)$ \\
\hline
\end{tabular}

"Solvent is methylene chloride in experimental value. Experimental value: uf-visible data is obtain from Korean Research Institute of Chemical Technology. 


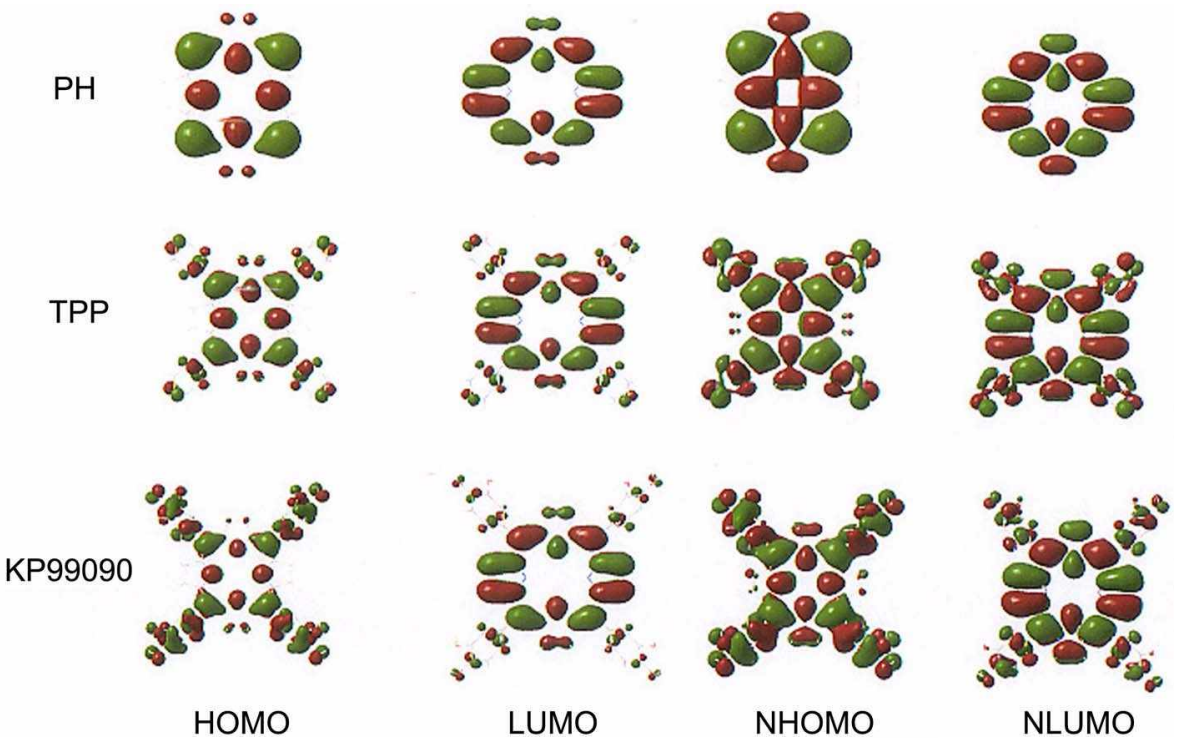

Figure 4. The molecular orbital contours of the HOMO, LUMO, NHOMO, and NLUMO for free-base porphyrins (PH), meso-tetra phenyl porphyrin (TPP), and meso-tetracatecholic porphyrin (KP99090) calculated from LSDA theory.
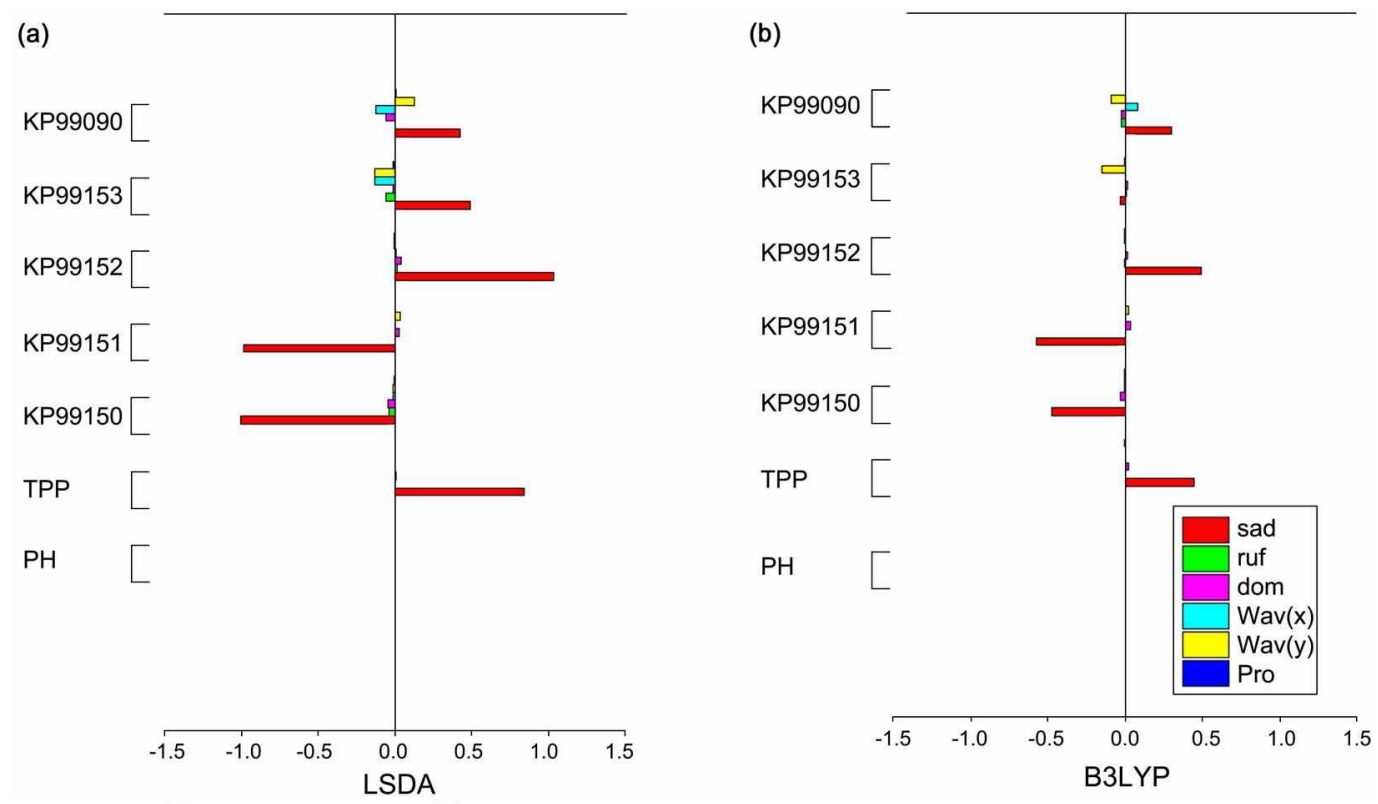

Figure 5. Out-of-plane defomations (in A) for calculated LSDA of the molecular systems (TPP, KP99150, KP99151, KP99152, KP99153, and KP99090) trom nomal coordinate structural decomposition. (a) Out-of-plane detomations for LSDA. (b) Out-of-plane defonmations for B3LYP.

A. doning is $0.04 \AA$, while saddling is $-0.98 \AA$, doming is $0.03 \AA$ for KP99151. Thus red shift for KP99151 is noted for deformation relative to KP99152.

The electronic effect of each catecholic group reduces the HOMO-LUMO gap and increases red shifts in Table 6. However the HOMO-LUMO gap of KP99152 is similar to that in KP99150, and larger than that of KP99151. Thus we examined these molecular systems with a question. The high enersy order of HOMO is KP99152. KP99151. and KP99150. while the order of LUMO is KP99152. KP99150, and KP99151. It is associated with out-of plane deformations of LSDA in Figure 5. The distortion of porphyrin macrocycle predominantly raises the energies of the HOMOs. so the net result is a large drop in HOMO and smaller drop in LUMO energies upon mesu-substituted catecholic group of the porphyrin macrocycle. These results are in reasonable agreenent with normal-coordinate structural decomposition (NSD) results.

\section{Conclusion}

1. We found following results from the DFT geometry optimization.

a) As compared the calculated bond lengths and angles of free-base porphyrin $(\mathrm{PH})$ with $\mathrm{x}$-ray crystallographic bond lengths and angles. the calculated RHF bond lengths and 
angles are in agreenent with maxinum differences of 0.006 0.007 A. 0. 1-0.4 degree for B3LYP/RHF bond lengths. and $0.017 \AA$ A. 0.3-0.8 degree for LSDA/RHF. Then B3LYP// RHF bond lengths angles are in excellent agreement with the experimental values of free-based porphyrin (see Table 1).

b) TPP substituted by phenyl groups at the meso-positions of free-base porphyrin increase the nearest $\mathrm{C}_{m e s 0}-\mathrm{C}_{\alpha}$ bond length in porphyrin ring by 0.011 to 0.012 for the B3LYP and by 0.013 to $0.014 \AA$ for the LSDA.

c) A series of meso-substituted catecholic porphyrins (KP99150, KP99151, KP99152. KP99153, and KP99090) increase the nearest $\mathrm{C} \cdot \mathrm{C}$. bond length in porphyrin ring by 0.012 to 0.014 for B3LYP and 0.014 to $0.015 \AA$ for LSDA. as compared to that of free-base porphyrin $(\mathrm{PH})$, due to catecholic group effects on the nearest $\mathrm{C}_{m e s / \alpha}-\mathrm{C}_{\alpha}$ bonds.

d) As compared to $\mathrm{C}-\mathrm{C}$ bond length of meso-tetraphenyl porphyrin (TPP). due to catecholic group effects on the nearest $\mathrm{C}_{\text {me.5o }}-\mathrm{C}_{\alpha}$ bonds. a series of meso-substituted catecholic porphyrins (KP99150. KP99151. KP99152, KP99153. and KP99090) increase the nearest $\mathrm{C}_{m e, s_{0}}-\mathrm{C}_{\alpha}$ bond length in porphyrin ring by 0.001 to 0.002 for B3LYP and by $0.001 \AA$ for LSDA. Then the bond lengths show sniall change. due to to catecholic group effects on the nearest $\mathrm{C}_{\text {miso }}-\mathrm{C}_{\alpha}$ bonds.

2. Although the effect on bond length is sniall, the calculated electronic structures clearly show the contribution of phenyl and catecholic group to $\pi$-electron conjugation for both $\mathrm{HOMO}$ and LUMO.

3. As compared B3LYP and LSDA energy gap, the wavelength due to B3LYP energy gaps is favored with experimental value in Soret (B). and LSDA energy gaps are favored with experimental value in visible bands (Q) (see Table 5).

4. The electronic effect of each catecholic group reduces the HOMO-LUMO gap. The HOMO-LUMO gap of KP99152 is similar to that in KP99150. and larger than that of KP99151.

5. From KP99150. KP99151. and KP99152. the distortion of porphyrin predominantly raises the energies of the HOMOs. so the net result is a large drop in HOMO and smaller drop in LUMO energies upon meso-substituted catecholic group of the porphyrin macrocycle. These results are in reasonable agreement with normal-coordinate structural decomposition (NSD) results.

6. The HOMO-LUMO gap is an important factor to consider in the development of photodynamic therapy (PDT).
Acknowledgments. The authors wish to acknowledge funancial from Ministry of Education (BK2l). Sung-Bae Park is thankful for support of a grant from Inje University (2006).

\section{References}

1. (a) Ghosh. A. In The Porplywin Handhook, Kardish, K. M: Smith. K. M.; Guilard, R.. Eds.: Academic Press: New York. 20006: Vol. 7. p 1. (b) Shelnutt. T. A. In The Porphnrin Handbootr. Kardish. K. M.: Smith. K. M.: Guilard. R.. Eds.: Academic Press: New York. 2000: Vol. 7. 167.

2. (a) Wasielewski, M. R. Chem. Rev, 1992, 92. 435. (b) Gust, D.; Moore. T. A.; Moore, A. L. Acc. Chem. Res. $2001,34.40$

3. Jasat, A.: Dolphin. D. Chem. Ren 1997, 97, 2267.

4. Ali. H.: vant Lier. T. E. Chent. Rev: 1999. 99. 2379.

5. Galezowski. M.: Gryko. D. T. J. Org. Chent. 2006. 71. 5942

6. Paney. R. K.: Zheng. G. In The Ponplnin Handbook. Kardish. K M.; Smith. K. M.: Guilard. R.. Eds.: Academic Press: New York. 2000: Vol. 6, 159

7. Edwards, L.: Dolphin, D. H:; Gouterman, M; Adler, A. D. J. 1/ol. Spectrose. 1971. 38.16

8. (a) Goutermant. M. J. Mol. Spectrose. 1961. 6. 138. (b) Takeuchi. T.: Gray. H. B.: Goddard III. W. A. J. An. Chem. Soc. 1994. 116 9730. (c) Wang. Z.: Day. P. N.; Pachter. R. J. Chem. Phws. 1998. 108.2504

9. Shelnutt, J. A.: Song, X. Z.: Ma. J. G.; Jia, S. L.; Jentzen. W: Medforth. C. J. Chem. Soc. Rev 1998. 27, 31.

10. Jentzen. W.: Ma. T. G.: Shelnutt. J. A. Biophns. J. 1998. 74. 753

11. Hohenberg. P.: Koht1. W. Phys. Rev: 1964. J36. B864.

12. Kohn1. W.: Sham. L. T. Phos Rer: 1965. 140. Al133.

13. Pople J. A.; Gill, P. M. W. Chem. Phus. Lett. 1992, 199.557.

14. Johnson, B. G.; Frisch, M. J. J. Chem. Plys. 1994. 100. 7429.

15. Vosko, S. J.: Wilk. L.: Nusair M. Can. J. Plws. 1980. 58. 1200.

16. Becke. A. D. J. Chent. Phys. 1993. 98.5648 .

17. Becke. A. D. J Chent Phis. 1996. 104. 1040

18. Frisch. M. J.: Trucks. G. W.: Schlegel. H. B.: Gill. P. M. W.: Tohnson. B. G.: Robb. M. A.: Cheeseman. J. R.; Keith, T.: Peterson. G. A.; Montgometry, J. A.: Raghavacari. K.: Al-Laham, M. A.: Zakrzewski, V. G. Ortiz, J. V.: Foresman. J. B.; Cioslowski, J:- Stefanov, B. B. Nanayaktara. A.: Challacombe. M.: Peng. C. J.: Ayala. P. Y: Chen. W.: Wong. M. W.: Andres. J. L.: Replogle. E. S.: Gomperts. R.: Martin. R. L.: Fox. D. L.: Binkley. J. S.: Defrees. D. J.: Baker. J. Stewart. J. P. Head-Gordon, M.; Gonzalez, C.: Pople. J. A. Gaussian, Inc: Pittsburgh. PA, 1999.

19. Lauher. J. W.; Ibers. J. A. J. Am. Chem. Soc, 1973, $95,5148$.

20. Rani. V. R.: Kishan. M. R.: Kulkarni. S. J.: Raghavan1. K. V. Catal. Conmt 2005. 6.531.

21. Song. Y.: Haddad. R. E.: Jia. S. L.: Hok. S.: Olmstead. M. M.: Nurco. D. J:; Schore, N. E.: Zhang. J.: Ma. J. G.; Smith, K. M; Gazeau. S.: Pecaut, J.; Marchon. J. C.: Medforth. C. J.: Shelnutt, J. A. d. Am. Chem. Soc. 2005. 127, 1179 . 